\title{
Experience gained from using three extra oral approaches to the neck of the mandibular condyle: A comparative study
}

\section{Reiadh K. Al-Kamali *}

\section{Abstract}

Background and objective: Surgical treatment of condylar diseases involves some problems concerning the choice of the surgical approach to the condylar neck that provides adequate exposure of the area with the least trauma to the facial nerve and parotid tissue. In this paper, personal experience with the surgical treatment of some mandibular condylar neck problems by the preauricular, submandibular and the retromandibular- transmasseteric approaches is reported.

Methods: Over the last 5 years, 52 condylar neck surgeries were carried out on 41 patients to treat 18 cases of condylar neck fractures, 19 cases of plate and bone graft fixation after resection of mandibular tumours and 4 cases of chronic pain and dysfunction of the TMJ. During follow-up, functions of the mandible and facial nerve branches were monitored as does the presence or absence of sialocele or parotid fistula. The appearance of the scar post- surgically and the quality of the access achieved by each type of the approaches to the condylar neck were also appraised.

Results: The incidence of apparent postoperative scar appeared most after the preauricular approach to the condylar neck and least after the submandibular approach. Difficulties in management of condylar neck fractures are found more with the preauricular and least with the retromandibular-transmasseteric approaches. Weaknesses in the branches of the facial nerve are noticed in $50 \%$ of the preauricular approaches, $6.89 \%$ of the retromandibular-transmasseteric approaches, and $47.36 \%$ of the submandibular approaches. In all of the patients, this problem lasted for 3-6 weeks to resolve spontaneously thereafter. All the patients in this work suffered limitation of jaw opening in the early postsurgical period. This problem was a transient one and due to pain and muscle spasm. However, persistent limitation of jaw opening is reported in $13.79 \%$ of the retromandibular-transmasseteric approaches and $47.36 \%$ of the submandibular approaches to the mandibular condyle.

Conclusion: Experience has shown that the retromandibular-transmasseteric approach to the condylar neck allows for good anatomical repositioning of the fractured condyle and direct access for precise positioning and fixation of the plate or bone graft to achieve satisfactory mandibular function with the least chance of trauma to the facial nerve and parotid tissues.

Keywords: Condylar neck surgery, preauricular, submandibular and retromandibulartransmasseteric approches.

\section{Introduction}

There are 4 main extra oral approaches for exposure of mandibular condyle. These include the preauricular, submandibular, preauricular-transparotid and retromandibular-transmasseteric approuches. They all expose one or the other of the facial nerve branches to the risk of damage and could sometimes leave an obvious scar even though the surgery is properly executed and the wound is properly closed ${ }^{1}$. The preauricular approach to the condylar neck is usually made through an incision placed anterior to the auricle and extended to the temporal region to facilitate exposure of the condylar neck. In spite of this

*Department of Oral and Maxillofacial Surgery, College of Dentistry, Hawler Medical University, Erbil, Iraq. 
http://dx.doi.org/10.15218/zjms.2014.0003

extension, this approach allows for limited access to the condylar neck and risk the temporal branch of the facial nerve to dam$\mathrm{age}^{2}$. The submandibular approach to the condylar neck risks the marginal mandibular branch of the facial nerve to trauma and does not allow for comfortable exposure of the condylar neck. This often makes adequate reduction of the fracture line and the application of fixation screws quite difficult. Furthermore, when this approach is used, fixation of the screws often has to be done through transbuccal route or by the use of an endoscope ${ }^{3}$. The preauriculartransparotid approach to the condylar neck is usually carried out through the facelift or retromandibular incision. In either case, the skin flap is elevated above the parotid fascia which is then cut by knife to expose the parotid tissue. The dissection is then taken blindly through the parotid tissue in a direction parallel to the anticipated branches of the facial nerve to reach the masseteric muscle which is split along its fibers to expose the condylar neck. Although this approach allows for direct access to the condylar neck, but it carries the risk of injury to the facial nerve and the parotid gland ${ }^{4}$. In the retromandibulartransmasseteric approach, the condylar neck is approached through an incision in the retromandibular area. The skin flap is taken forward to expose the anteroinferior edge of the parotid gland. An incision is then made parallel to this edge to expose the masseter muscle which is split along its fibers to expose the underlying bony ramus. The split through the muscle may be extended superiorly as needed to expose the condylar neck ${ }^{5}$. The aim of this work is to analyze the experience gained from approaching the condylar neck through three different surgical approaches.

\section{Methods}

Fourty one adult patients underwent 52 surgeries on the condylar neck in the period from July 2007 until October 2011. Of these patients, 18 were with fractures of the condyle, 19 were with tumours involving the mandible, , and 4 were with intractable pain and dysfunction of the temporomandibular joint. Those patients with neurological deficit affecting the facial nerve were excluded from this work. Cancer patients with their submandibular lymph node involved by the tumour were also excluded from this study. The criteria for selecting surgical treatment for the fracture condylar neck include more than $5 \mathrm{~mm}$ shortening of the ramus and/or more than 30 degree angulation at the fracture site ${ }^{6}$. Presurgical radiological imaging of the mandibular ramus and condyle included the OPT, PA of the mandible (or reverse Towne's view), and CT scan of the mandible. In the fracture cases, the OPT is used to calculate the ramal height and condylar angulations in the sagittal plane, whereas the reveres Town's view is used to calculate the condylar angulations in the coronal plane. Three types of surgical approaches have been used in this work; they are the retromandibular-transmasseteric, submandibular and preauricular.approaches. In this work the retromandibulartransmasseteric approach has been modified to reduce the chances of damage to the parotid gland and the facial nerve. This approach is started by surface land marking of the anterior border of the parotid gland as shown in, Figure 1.

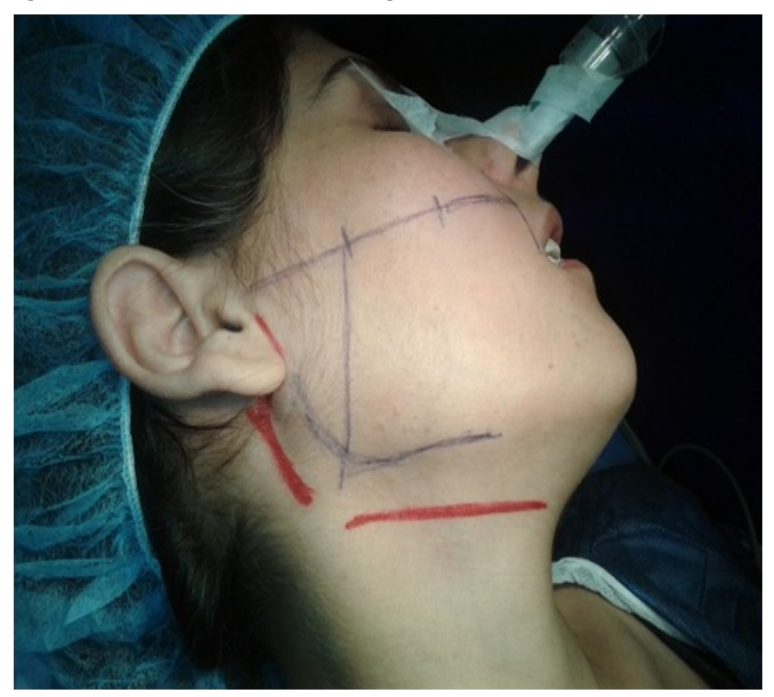

Figure 1: Surface land marking of the anterior border of the parotid gland 
A line is drawn from the lowest point of the alar cartilage to the angle of the mouth. This line is bisected and the midpoint is joined with a straight line to the most posterior point of the tragus. The line is then divided into three equal parts. The middle section corresponds to the position of the parotid duct ${ }^{7}$. A third line is then drawn connecting the posterior end of this section to the mandibular angle. This (third) line corresponds to the position of the anterioinferior border of the parotid gland. For a safer surgery, the buccal branch of the facial nerve is marked leaving the anterioinferior border of the parotid gland $1 \mathrm{~cm}$ below the course of the parotid duct to run foreword and parallel to it ${ }^{8}$. The marginal mandibular branch of the facial nerve, on the other hand, is marked leaving the anterio-inferior border of the parotid gland $1 \mathrm{~cm}$ superior to the lower border of the mandible to run foreword and parallel to $\mathrm{it}^{8}$. The retromandibular incision is placed through the skin from just below and $1 \mathrm{~cm}$ posterior to the ear lobe. It is taken inferiorly and parallel to the posterior border of the mandible to a point level and $1 \mathrm{~cm}$ posterior to the mandibular angle. For a wider access the superior end of this incision may be taken around the ear lobe in a nice anterior curve to just below the tragus. The skin flap is reflected superior to the parotid fascia and taken anteriorly until the line corresponding to the anterior border of the parotid gland is reached. When this line has been reached the dissection is taken medially, through the masseter muscle, along the anterior border of the parotid. The masseter is split in the direction of its fibres in the area confined between the superior marking of the buccal branch of the facial nerve and the inferior marking of the marginal mandibular branch of the facial nerve. The medial dissection is continued until the ramus and the condylar neck is reached. When the submandibular approach is used, the skin incision is placed in a skin crease at least $2 \mathrm{~cm}$ below the lower margin of the mandible and marginal mandibular branch of the facial nerve is protected by keeping the dissection medial to the deep cervical fas$\mathrm{cia}^{8}$. Postoperative care and follow-up:

Vacuum drain were used for all patients and removed 1-3 days postoperatively. All of the patients were put on short term IMF (7-10 days), and were encouraged to exercise mouth opening and closure afterword.

Every patient is seen 1 weak later for stitches removal, release of the IMF, and for checking the appearance of the wound. The amount of jaw opening, function of the facial nerve branches, and the presence of sialocele or parotid fistula are also checked. Postoperative OPG view is obtained at this visit and arrangement is made to see the patient again 1,3 and 6 months for following up. The intra- and postoperative complications with the use of these surgical approaches were studied to show the advantages of either one approach over the others. This is achieved by using the Epi Info program, version 3,5,4, by which the chi-square test used for determination of association between variables, and $p$-values equal or less than 0.05 is considered as statistically significant.

\section{Results}

Eighteen (43.90\%) out of 41 patients has had the condylar neck surgery performed to treat their fracture condyles. On the other hand, 19 (46.34\%) patients has had the condylar neck surgeries done for exposure of the condylar neck during resection of a mandibular tumour. The other 4 $(9.75 \%)$ patients had the condylar neck surgery carried out for condylotomy, Table 1. Four $(22.22 \%)$ out of 18 patients underwent condylar neck surgery because of more than $5 \mathrm{~mm}$ shortening of the mandibular ramus in the fracture side. For 6 $(33.33 \%)$ out of the 18 trauma patients, the condylar neck surgery is performed because they had more than 30 degrees angulation of the condylar neck in the fracture side. The other $8(44.44 \%)$ trauma patients has had the condylar surgery performed to avoid putting them on long term (45days) IMF, Table 2. In 19 (46.34\%) out of 41 patients, the condylar surgery has 
been carried out during resection of tumors from the mandible. Twelve $(63.15 \%)$ of these patients has had malignant tumours involvement of the mandible by carcinomas from the mouth floor or the retromolartrigone. The condylar surgeries in these patients were performed to allow for fixation of a plate after mandibular resection. The condylar surgery for the other 7 $(36.84 \%)$ patients were used for fixation of a bone graft after mandibular resection for benign tumour, Table 3 . Three types of surgical approaches have been used in this work; the retromandibular-transmasseteric, submandibular and the preauricular approaches. Each one of these approaches either been used alone or in combination with another approach. The retomandibular -transmasseteric approach has been used $29(70.73 \%)$ out of 52 condylar neck surgeries (18 trauma and 11tumours). The submandibular approach to the condylar neck has been used in $19(36.53 \%)$ out of 52 (5 in combination to treat 12 cancer patients, 7 as a sole approach to treat cancer cases, 6 in combination to treat 7 patients with benign tumours in the mandible and once as a sole treatment of benign tumour in the mandible). The preauricular approach to the condylar neck has been used to treat 4 cases of chronic intractable pain and dysfunction of the TMJ, Table 4. Complications reported in this work include the formation of apparent scar, difficulty with accessing the condylar region, weakness one or more than one of the facial nerve function and limitation of jaw opening. Sialocele and parotid fistula were not reported in this work. The incidence of apparent postoperative scar appeared most after the preauricular approach to the condylar neck and least after the submandibular approach. Difficulty in reduction of the fracture, application of plating and vision is found more with the preauricular and least with the retromandibular-transmasseteric approaches. Weakness in the temporal branch of the facial nerve is only noticed in $50 \%$ of the preauricular approaches to the condylar neck. On the other hand, $6.89 \%$

the retromandibular-transmasseteric approaches in this study had weakness in the buccal branch of the facial nerve, and $47.36 \%$ of the submandibular approaches were followed by transient weakness in the marginal mandibular branch of the facial nerve. The weakness in the branches of the facial nerve was a transient problem and lasted for 3-6 weeks to resolve spontaneously thereafter. All the patients in this work suffered limitation of jaw opening in the early postsurgical period. This problem was a transient one and due to pain and muscle spasm. However, persistent limitation of jaw opening is reported in $13.79 \%$ of the retromandibular-transmasseteric approaches and $47.36 \%$ of the submandibular approaches to the mandibular condyle, Table 5.

Table 1: Indications for condylar neck surgery surgery

\begin{tabular}{ll} 
Indication & Number (\%) \\
\hline $\begin{array}{l}\text { ORIF after condylar frac- } \\
\text { tures }\end{array}$ & $18(43.90)$ \\
$\begin{array}{l}\text { Exposure of the condylar } \\
\text { neck during resection of }\end{array}$ & $19(46.34)$ \\
$\begin{array}{l}\text { a mandibular tumour } \\
\text { Condylotomy for MPDS }\end{array}$ & $4(9.75)$ \\
Total & $41(100)$
\end{tabular}

ORIF= Open Reduction with Internal Fixation

Table 2: Indications surgery for patients with fractures of the condylar neck

\begin{tabular}{ll} 
Indication & Number (\%) \\
\hline $\begin{array}{l}\text { More than } 5 \mathrm{~mm} \text { shortening of } \\
\text { the mandibular ramus in the }\end{array}$ & $4(22.22)$ \\
fracture side & \\
More than 30 degrees angula- & $6(33.33)$ \\
tion of the condylar neck in & \\
the fracture side & \\
Avoidance of full term inter- & $8(44.44)$ \\
maxillary fixation & $18(100)$ \\
Total &
\end{tabular}


Table 3: Indications for condylar neck surgery during excision of mandibular tumours

Indication

Fixation of a plate after mandibular resection for cancer

Fixation of a bone graft after mandibular resection for benign tumour

Total
Number (\%)

Table 4: Types and numbers of surgical approaches to the condylar neck

Type of Surgical Approach

Retromandibular-transmasseteric

Submandibular

Preauricular

Total
Number $(\%)$

$29(55.76)$

$19(36.53)$

$4(7.69)$

$52(100)$

Table 5: Incidence of complications among the different approaches to the condylar neck

\begin{tabular}{|c|c|c|c|c|}
\hline Complication & $\begin{array}{l}\text { Preauricular } \\
\text { Approach }\end{array}$ & $\begin{array}{l}\text { Retromandibular- } \\
\text { Transmasseteric } \\
\text { Approach }\end{array}$ & $\begin{array}{l}\text { Submandibular } \\
\text { Approach }\end{array}$ & p-value \\
\hline Apparent scar & $3(75 \%)$ & $6(20.68 \%)$ & $3(15.78 \%)$ & $\begin{array}{l}0.03 \\
S\end{array}$ \\
\hline $\begin{array}{l}\text { Difficulty in vision, } \\
\text { reduction of fracture } \\
\text { and application of } \\
\text { plate }\end{array}$ & $4(100 \%)$ & $2(6.89 \%)$ & $10(52.63 \%)$ & $\begin{array}{l}<0.001 \\
\text { H.S. }\end{array}$ \\
\hline $\begin{array}{l}\text { Weakness in the } \\
\text { frontal branch of the } \\
\text { facial nerve }\end{array}$ & $2(50 \%)$ & $0(0 \%)$ & $0(0 \%)$ & $\begin{array}{l}<0.001 \\
\text { H.S. }\end{array}$ \\
\hline $\begin{array}{l}\text { Weakness in the } \\
\text { buccal branch of the } \\
\text { facial nerve }\end{array}$ & $0(0 \%)$ & $2(6.89 \%)$ & $0(0 \%)$ & $\begin{array}{l}0.43 \\
\text { N.S. }\end{array}$ \\
\hline $\begin{array}{l}\text { Weakness in the } \\
\text { mandibular branch of } \\
\text { the facial nerve }\end{array}$ & $0(0 \%)$ & $0(0 \%)$ & $9(47.36 \%)$ & $\begin{array}{l}<0.001 \\
\text { H.S. }\end{array}$ \\
\hline $\begin{array}{l}\text { Persistent limitation of } \\
\text { jaw opening }\end{array}$ & $0(0 \%)$ & $4(13.79 \%)$ & $9(47.36 \%)$ & $\begin{array}{l}0.01 \\
S\end{array}$ \\
\hline $\begin{array}{l}\text { Persistent deviation } \\
\text { with jaw opening }\end{array}$ & $1(25 \%)$ & $2(6.89 \%)$ & $2(10,52)$ & $\begin{array}{l}0.5 \\
\text { N.S. }\end{array}$ \\
\hline Sialocele & $0(0 \%)$ & $0(0 \%)$ & $0(0 \%)$ & N.A. \\
\hline Parotid fistula & $0(0 \%)$ & $0(0 \%)$ & $0(0 \%)$ & N.A. \\
\hline
\end{tabular}

H.S.=Highly Significant, N.S.= Not Significant, S= significant, N.A.=Not Applicable 


\section{Discussion}

Those patients with neurological deficit affecting the facial nerve were excluded from this work in order not to confuse the study's end results. Likewise cancer patients with involvement of the submandibular lymph node by the tumour were also excluded from this study as their surgery will necessitate excision of the marginal mandibular. The scar formation after the retromandibular-transmasseteric incision is mainly related to the fact that this incision is of necessity longer than that used in other approaches. This comes in agreement with other studies 1,5 , but it is my impression that the preauricular element of the retomandibular-transmasseteric incision is not cosmetically important. This is because the anterior part of it is in the skin crease anterior to the ear lobe, and its posterior part is hidden by the later structure. It is the retromandibular extension that can leave an obvious scar, but I tried to keep it to minimum by meticulous closure of the wound and early removal of the stitches. As to the issue of access, our experience is in agreement with others that the preauricular approach to the condylar neck is very unsatisfactory for reduction of condylar fracture or placement of a plate for fixation ${ }^{3}$. It is also my impression, like that of others that this approach is probably, useful only for the upper half of the condylar neck for condylotomy ${ }^{9}$. The submandibular approach often necessitates wide stripping of the masseter muscle off the ramus and forceful tissue retraction to access the condylar neck. This can be traumatic to the tissues and causes limitation of jaw opening for periods longer than that experienced after the use of other approaches. Using this approach would also enforce oblique insertion of the plates and screws which may render the final results of reduction of condylar fracture, in cases of trauma, unsatisfactory ${ }^{10}$. The retromandibular-transmasseteric approach, on the other hand, has proved very adequate for all surgeries on the condylar neck. My experience in this matter comes in agreement with the experience of oth$\mathrm{ers}^{4,5}$. The marginal mandibular branch is most often injured in the submandibular, whereas the preauricular approach often causes injury to the temporal and zygomatic branches. The retromandibulartransmasseteric approach, however, appears safer to the marginal mandibular branch of the facial nerve from the submandibular approach, but can cause injury to the buccal branch of the facial nerve. Others experience agreed with these observations and agreed to the temporary nature of these weakness ${ }^{2,5,11}$. When performing the retromandibular- transmasseteric approach to the condylar neck, it is my practice to keep the medial dissection between the buccal and the marginal mandibular branches of the facial nerve reduces the chance of damage to either of them to the minimum. The literature shows the same practice by others to approach the condylar neck through the retromandibular-transmasseteric or the retromandibular-transparotid incisions ${ }^{5,12}$. Persistent limitation of jaw opening is noticed more of a problem after the submandibular approach to the condylar neck. This is obviously because of the need for wider stripping of the masseter muscle off the ramus than it was needed with the retromandibular-transmasseteric approach ${ }^{1}$. This problem can be overcome by jaw exercise, and our experience is that the pain associated with the exercises is less with the least stripping of the masseter muscle. Parotid fistula and sialocele were reported as a complication after the preauricular, retromandibular-transparotid, and the submandibular approaches to the mandibular condylar neck ${ }^{2,12}$. The main reason for this complication was the cut in the capsule that has been used to approach the underlying masseter muscle ${ }^{12}$. However, the parotid capsule has not been violated by the retromandibular-transmasseteric approaches to the condylar neck used in this work. This may explain the absence of sialocele and parotid fistula as a complication in this study. 


\section{Conclusion}

The preauricular approach to the condylar neck is probably adequate for accessing the upper half of the condylar neck, but not for controlling a fracture or applying a plate. The submandibular approach alone is adequate for approaching the lower half of the neck, but again less than adequate for reduction of a fracture or application of plate fixation. Finally, the retromandibulartransmasseteric approach to the condylar neck is very satisfactory as an approach to the condylar neck. Furthermore, this approach causes least trauma to the facial nerve and parotid tissue.

\section{References}

1. Haug RH, Assael LA. Outcomes of open versus closed treatment of mandibular subcondylar fractures. J Oral Maxillofac Surg 2001; 59:370-5.

2.Dolwick MF, Kretzschmar DP. Morbidity associated with the preauricular and perimeatal approaches to the temporo-mandibular joint. J Oral Maxillofac Surg 1982; 40:699-700.

3.Chen CT, Lai JP, TungTC, Chen YR.Endoscopically assisted mandibular subcondylar fracture repair. Plast Reconstr Surg1999; 103:60-5.

4.Vesnaver A, Gorjanc M, Eberlinc A, Dovsak DA, Kansky AA. The periauriculartransparotid approach for open reduction and internal fixation of condylar fractures. J Craniomaxillofac Surg 2005; 33:169-79.

5.Wilson AW, Ethunandan M, Brennan PA, Transmassetericantero-parotid approach for open reduction and internal fixation of condylar fractures. Br J Oral Maxillofac Surg S 2005; 43:5760

6.Schneider M, Erasmus F, Gerlach KL, Kuhlisch E, Loukota RA, Rasse M. Open reduction and internal fixation versus closed treatment and mandibulomaxillary fixation of fractures of the mandibular condylar process: a randomized, prospective, multicenter study with special evaluation of fracture level. J Oral Maxillofac Surg 2008; 66:253744

7.Langdon JD. Parotid surgery. In Langdon JD, Patel MF, Ord RA, Brennan PA. Operative oral and maxillofacial surgery, 2nd ed. London: Hodder Arnold, an Hachette UK Company; 2011. P. 390.

8.Davis BA, Anson BJ, Budinger JM, Kurth LE. Surgical anatomy of the facial nerve and parotid gland based upon a study of 350 cervicofacial halves. Surg Gynecol Obstet 1956; 102:385-412.

9.Banks P, MacKenenzie I: Condylotomy. A clinical and experimental appraisal of a surgical technique. J Maxillofac Surg 1975; 3:170-81.
10.Marker P, Nielsen A, Lehmann-Bastian H. Fractures of the mandibular condyle. Part 2: Results of treatment of 348 patients. $\mathrm{Br} \mathrm{J}$ Oral Maxillofac Surg 2000; 38:422-6.

11. Ellis E, McFadden D, Simon $P$.surgical complications with open treatment of mandibular condylar process fractures. J Oral Maxillofac Surg 2000; 58(9):950-8.

12.Downie JJ, Devlin MF, Carton ATM, Hislop WS. Prospective study of morbidity associated with open reduction and internal fixation of the fractured condyle by the transparotid approach. $\mathrm{Br} \mathrm{J}$ Oral Maxillofac Surg 2009; 47:370-3. 